\title{
Effects of temperature on embryonic development of the Humboldt squid Dosidicus gigas
}

\author{
Danna J. Staaf ${ }^{1, *}$, Louis D. Zeidberg ${ }^{1,2}$, William F. Gilly ${ }^{1}$ \\ ${ }^{1}$ Hopkins Marine Station, Stanford University, Oceanview Boulevard, Pacific Grove, California 93950, USA \\ ${ }^{2}$ California Department of Fish and Game, Marine Region, 20 Lower Ragsdale Drive, Suite 100, Monterey, California 93940, USA
}

\begin{abstract}
Little is known about embryonic development of oceanic squids, yet such information is critical to a meaningful understanding of these ecologically and economically important species. Eggs of the Humboldt squid Dosidicus gigas were artificially fertilized and incubated at temperatures found throughout this species' range $\left(5\right.$ to $\left.30^{\circ} \mathrm{C}\right)$. Successful development through hatching was observed only between 15 and $25^{\circ} \mathrm{C}$, and the rate of development increased with increasing temperature. Previous work reported a D. gigas egg mass at the pycnocline in the Gulf of California, suggesting that successful embryonic development can occur only in those areas of the eastern Pacific where temperature at the pycnocline is between 15 and $25^{\circ} \mathrm{C}$. Analysis of available oceanographic data revealed a vast area relatively close to the California coast that is seasonally suitable for development of $D$. gigas embryos. Spawning offshore in this region may thus be an important factor supporting the $D$. gigas populations that invaded coastal waters of the Pacific Northwest after 2005.
\end{abstract}

KEY WORDS: Development $\cdot$ Dosidicus gigas $\cdot$ Humboldt squid $\cdot$ Temperature effects $\cdot$ In vitro fertilization $\cdot$ Range expansion $\cdot$ Parthenogenesis

\section{INTRODUCTION}

Embryonic development of squids has been most thoroughly studied in nearshore loliginid species that lay eggs in shallow water or in the laboratory. Naef (1928) used Loligo vulgaris to generate the first set of developmental stages for cephalopod embryos. This early work guided later studies on $L$. pealeii, which resulted in the description of 30 distinct developmental stages (Arnold 1965) that were adopted for subsequent embryological research on other species of squid (Segawa et al. 1988, Sakurai et al. 1996).

Spawned eggs are much more difficult to obtain from oceanic species. Squids of the oceanic family Ommastrephidae are particularly important to both pelagic ecosystems and commercial fisheries (Caddy \& Rodhouse 1998), but these species spawn in the relatively inaccessible open sea (O'Dor et al. 1982) so little is known of their spawning requirements or behavior (Clarke 1966). This lack of information is notable for a group that comprises the largest invertebrate fisheries in the world. Since 2004, the ommastrephid Dosidicus gigas has been the largest squid fishery for all years but 2007 and has been ranked 12th internationally among all fished species in terms of landings (averaging $>750000 \mathrm{t} \mathrm{yr}^{-1}$, see ftp.fao. org/fi/stat/summary/a1e.pdf). Artificial fertilization has provided a valuable alternative to naturally spawned eggs for embryological study in the family Ommastrephidae.

Artificial fertilization of squid eggs has been conducted for over a century (Watase 1891), but for many years, artificially fertilized eggs have arrested development before organogenesis due to the chorionic membrane's failure to expand to accommodate the developing embryo (Arnold 1974). This problem was initially overcome by Klein \& Jaffe (1984), who successfully cultured artificially fertilized eggs of Loligo pealeii through hatching on a layer of agarose jelly. Arnold \& O'Dor (1990) subsequently replaced 
agarose with a more natural material created from the freeze-dried accessory nidamental glands of $L$. pealeii and obtained chorion expansion in 4 oceanic squid species, one of which (Sthenoteuthis oualaniensis) produced viable hatchlings.

Attempts to identify an analogous natural material from an ommastrephid rather than a loliginid source revealed that only material from oviducal glands was effective in supporting chorion expansion (Sakurai \& Ikeda 1994, Ikeda \& Shimazaki 1995). The use of oviducal gland material led to successful development through hatching of artificially fertilized embryos of Todarodes pacificus (Sakurai \& Ikeda 1994, Watanabe et al. 1996), Sthenoteuthis oualaniensis and Ommastrephes bartramii (Sakurai et al. 1995), and Dosidicus gigas (Yatsu et al. 1999). Despite these successes, little subsequent work has been carried out on artificially fertilized eggs of ommastrephid species (Staaf et al. 2008).

Embryonic development of Dosidicus gigas and its temperature dependence is of particular interest in the context of the recent northward range expansion of this large predator in the California Current system over the past decade (Zeidberg \& Robison 2007). Adults have been shown to consume a wide variety of fish, crustaceans, and molluscs (Bazzino et al. 2007, Field et al. 2007), some of which are of considerable ecological and commercial importance (Field et al. 2010). Although adults of D. gigas appear to have become abundant in the California Current, whether they spawn in these relatively cold waters or migrate to warmer waters to spawn is unknown. Spawning areas for D. gigas have been reported in the Gulf of California (Gilly et al. 2006a, Camarillo-Coop et al. 2011), the Pacific Ocean off the Baja California Peninsula (Camarillo-Coop et al. 2006), Peru (Anderson \& Rodhouse 2001), and the Eastern Tropical Pacific, although a positive identification of species was not made in this case (Vecchione 1999).

Thermal limits for successful embryonic development in Dosidicus gigas are unknown. Previous studies on temperature dependence of embryonic development in the ommastrephids Illex illecebrosus (O'Dor et al. 1982) and Todarodes pacificus (Sakurai et al. 1996) have yielded useful insights into environmental tolerance pertaining to spatial distribution and migration to suitable fishing and spawning grounds (Sakurai et al. 2000). In the present study, this approach is extended to D. gigas in order to address the question of spawning in the cold California Current. Previous work (Staaf et al. 2008) is expanded with observations on unfertilized eggs, alterations of the artificial fertilization technique, and temperature treatments over an ecologically relevant range. The results of the present study identify a thermal window for successful development through hatching that may preclude successful natural spawning in most of the northern California Current system. A putative seasonal spawning area is identified off the North American Pacific coast that may be relevant to range expansion of this species.

\section{MATERIALS AND METHODS}

Specimens of Dosidicus gigas were captured with jigs on hand lines or by rod and reel. They were immediately euthanized by decapitation and their mantles opened with a ventral cut. Collections were made in the northern hemisphere from 3 main areas: the California Current off the US Pacific Coast (CA, i.e. California and Oregon), the southern Gulf of California, Mexico (GOC), and the equatorial Eastern Tropical Pacific (ETP) (Table 1, Fig. 1). Sampling in CA was carried out with a small NOAA vessel (SC08: December 31, 2008, Soquel Canyon in Monterey Bay) and sport-fishing vessels 'Hulicat' (HMB09: January 11, 2009, Half Moon Bay) and 'New Seaforth' (SD10: February 1, 2010, San Diego). GOC collections were made with the RV 'New Horizon' (GB06: June 8 to 22, 2006, and GB07: May 29 to June 15, 2007, Guaymas Basin) and the 'Don Jose' (FB08: May 10 to 16, 2008, Farallon Basin). ETP samples were collected with the RV 'MacArthur II' (ETP06: October 6 to November 2, 2006).

Table 1. Dosidicus gigas. Details of adult collections made in 3 regions: California (CA), Gulf of California (GOC) and Eastern Tropical Pacific (ETP). Each set of artificial fertilization experiments is given a unique identity (Station) based on location and year. For each experiment, the month of collection, number of females from which eggs were extracted, female stage of maturity and whether the sperm was sourced from a male $(\mathrm{M})$ or female $(\mathrm{F})$ is indicated

\begin{tabular}{|lcccc|}
\hline Station & Month & No. of females & Stage & Sperm \\
\hline CA & & & & \\
SC08 & Dec & 1 & V & M \\
HMB09 & Jan & 1 & IV & M \\
SD10 & Feb & 3 & V & M \\
GOC & & & & \\
GB06 & May & 7 & V & M, F \\
GB07 & Jun & 2 & V & M \\
FB08 & May & 2 & V & M, F \\
ETP & & & & \\
ETP06 & Oct & 1 & IV & M \\
\hline
\end{tabular}




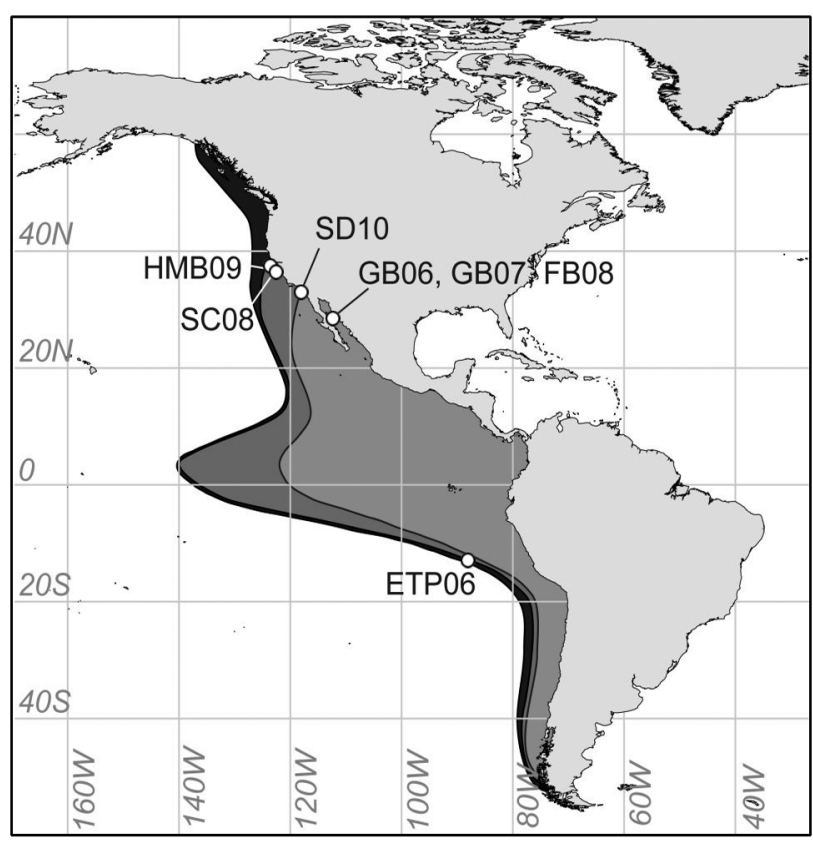

Fig. 1. Dosidicus gigas. Biogeographic distribution of Humboldt squid in the eastern Pacific, including recent range expansion. Historical range is shaded medium gray (Wormuth 1976), additional 2001 range is dark gray (Nigmatullin et al. 2001), and additional 2006 range is black (adapted from Gilly 2006 and Young \& Vecchione 2009). White circles mark locations where adult $D$. gigas were sampled to collect gametes for artificial fertilization. See Table 1 for list of stations

\section{Preparing oviducal gland powder}

Oviducal glands were extracted from mature female Dosidicus gigas and frozen at $-20^{\circ} \mathrm{C}$ for up to 1 yr. For lyophilization, frozen glands were cut with a razor blade, and small (ca. $1 \mathrm{~cm}^{3}$ ) pieces were inserted into round-bottomed cryovials (Nunc, Roskilde) containing a stainless-steel ball bearing (Spheric-Trafalgar) of the type used to grind tissue for stable-isotope analysis (Smith et al. 1996). Each open vial was covered with a folded Kimwipe EX-L (Kimberly-Clark) affixed with a rubber band around the neck of the vial. The vials were packed into a lyophilizer (Labconco) and freeze-dried for $72 \mathrm{~h}$ until completely dry.

After lyophilization, the Kimwipe was removed and the vials were capped and shaken individually with a Wig-L-Bug shaker (Crescent Dental Manufacturing). The presence of the ball bearings within the vials caused the dried gland to be ground into a fine powder. These vials of oviducal gland power were kept frozen at $-20^{\circ} \mathrm{C}$ until use.

\section{Gamete collection}

Reproductive maturity of Dosidicus gigas is identified by 6 stages: I, immature; II and III, maturing; IV and V, mature; VI, spent (Lipiński \& Underhill 1995). Ripe, orange-colored eggs are characteristic of both Stage IV and V females (Nigmatullin \& Markaida 2008), and eggs from both Stage IV and V females were used for artificial fertilization (Table 1). Stage VI females were never seen or caught. Oviducts and the attached oviducal glands were manually removed without cutting, and the ripe eggs were harvested by either cutting the oviduct open with a clean razor blade or allowing the eggs to drip out through the oviducal gland. No qualitative difference in developmental success was noted between these 2 techniques for egg extraction.

Female Dosidicus gigas can store viable sperm for some time after copulation (Markaida \& SosaNishizaki 2001), and spermatangia (spermatophores attached to the skin) and spermathecae (sperm-filled seminal receptacles) were found in the buccal area of all mature females examined. Stored sperm from both sources was used for artificial fertilization. Spermatangia were pulled free with blunt-tipped tweezers, and sperm was extracted from spermathecae by squeezing the base with sharp-tipped tweezers. In both cases, sperm was then wiped off the tweezers into a small glass dish. Spermatophores were also collected from mature males from either the spermatophoric sac or the mantle cavity after extrusion from the penis. Whenever possible, gametes were used for artificial fertilization within 1 to $2 \mathrm{~h}$ (GB06, ETP06, GB07), but when a delay was unavoidable, gametes were kept at $10^{\circ} \mathrm{C}$ for $12 \mathrm{~h}$ (GB06) or at $\sim 4^{\circ} \mathrm{C}$ for 6 to 48 h (FB08, SC08, HMB09, SD10). Freezing gametes at $-20^{\circ} \mathrm{C}$ for $12 \mathrm{~h}$ (GB07) did not support successful development, and these experiments were not included in the analysis of temperature effects on development.

\section{Artificial fertilization}

All artificial fertilization work followed standard techniques used for primary tissue-culture, with the work area maintained as clean as possible. Sterile tissue-culture plastic-ware was used, and natural seawater was always filtered through a $0.2 \mu \mathrm{m}$ filter. In general, methods followed those of Sakurai \& Ikeda (1994), Sakurai et al. (1996) and Yatsu et al. (1999), with the additional step of adding $25 \mathrm{mg} \mathrm{l}^{-1}$ each of ampicillin/penicillin and streptomycin (HyClone) to 
Table 2. Dosidicus gigas. Chorion expansion and survival of embryos for 2 different orders of procedural events with and without antibiotics. Antibiotic was added $22 \mathrm{~h}$ after fertilization or not at all. Survival was assessed $45 \mathrm{~h}$ after fertilization. Chorion expansion was measured as the mean \pm SD chorion:embryo ratio determined from photographs as the longest dimension of the chorion divided by the longest dimension of the embryo. Data were obtained from the Guaymas Basin 2006 (GB06) experiment

\begin{tabular}{|lccc|}
\hline Antibiotics & $\mathrm{N}$ & \% survival & Chorion:embryo \\
\hline Water first & & & \\
$\quad$ No & 33 & 15 & $1.18 \pm 0.10$ \\
Yes & 42 & 74 & $1.17 \pm 0.06$ \\
Water last & & & \\
No & 38 & 8 & $1.20 \pm 0.07$ \\
Yes & 36 & 67 & $1.17 \pm 0.07$ \\
\hline
\end{tabular}

the filtered seawater (Rosa \& Seibel 2010). GB06 experiments tested the importance of this antibiotic treatment by maintaining control eggs without antibiotics. A significant positive effect of antibiotics on embryo survival (Table 2, Pearson's chi-squared test: $\chi^{2}=50.7, \mathrm{df}=1, \mathrm{p}<0.001, \mathrm{n}=149$ ) led to their continued use in all other experiments.

Lyophilized oviducal gland powder prepared as described above was stirred into seawater (ca. $1 \mathrm{mg}$ $\mathrm{ml}^{-1}$ ) to make $0.1 \%$ 'jelly water.' Spermatophores or spermatangia were placed in a small, dry dish and chopped into small pieces with a razor blade. Seawater was then added to the dish to make 'sperm water.' Alternatively, sperm extracted from spermathecae was simply diluted into seawater. In all cases motility was observed under a microscope before sperm water was used for fertilization. Sperm from spermatophores, spermatangia, and spermathecae all resulted in successful fertilization (GB06, FB08), although post-fertilization developmental success was not individually quantified for the 3 sources.

GB06 experiments tested the effect of order of procedural steps when performing artificial fertilization. Sakurai et al. (1995) found that eggs must be immersed in seawater before they can be successfully fertilized but that pre-treatment of eggs with jelly water was better accomplished with eggs that had not been immersed. Their protocol settled on adding sperm and jelly water to eggs prior to adding seawater.

This protocol was used for 'water last' treatments. Eggs were extracted from a female as described above and placed in a dry dish. Spermatophores were chopped as previously described, but water was not added to them. Instead, the chopped pieces were spread over the eggs with tweezers. Jelly water was added, and after 15 min the dish was filled with seawater. For 'water first' treatments, eggs were extracted from the oviduct and transferred with a plastic pipette into a tissue-culture dish filled with seawater. First sperm water and then jelly water were added to the immersed eggs.

No significant difference between these procedural orders on developmental success (Table 2, Pearson's chi-squared test: $\chi^{2}=1.57$, df $=1, p=0.21$, $\mathrm{n}=149$ ) led to standardization of the fertilization procedure. Eggs were placed in a dish, sperm water and then jelly water were added, and sufficient additional filtered seawater was used to fill the dish. Dishes were kept covered.

Starting with FB08 experiments, eggs were rinsed before and after fertilization by stirring them gently with a pipette in filtered seawater. They were then pipetted into another clean dish with seawater, which was followed by another rinse (after Arnold \& O'Dor 1990).

\section{Embryo care and staging}

Approximately 100 eggs were fertilized in each individual dish (50 $\mathrm{mm}$ diameter), with the exception of SD10, when thousands of eggs were fertilized in a larger glass dish (100 mm diameter). In this case, successfully developing (cleaving) embryos were identified by observation with a stereomicroscope and gently removed 12 to $24 \mathrm{~h}$ after fertilization with a glass pipette into the smaller culture dishes (10 embryos each).

Water was changed once daily (twice in GB06) by pipetting out fluid until the embryos were only just covered and then adding clean seawater, or by gently pipetting the eggs into a clean dish filled with clean seawater. The former technique was used when new dishes were limited and the latter when they were not. Dead embryos were removed as soon as they were observed.

In most cases embryos were photographed at the time of a seawater change. Developmental stages of embryos were later assessed from these photographs. For GB06, FB08, SC08, and SD10, embryos were staged throughout each experiment and grouped into 5 developmental categories based on a modified version of the staging scheme of Watanabe et al. (1996) (see 'Results: Embryonic staging', Table 3). For SD10 experiments, the developmental stage of each of the 10 embryos was visually assessed under the microscope and noted. 
Table 3. Dosidicus gigas and Todarodes pacificus. Developmental categories for pre-hatching embryogenesis

\begin{tabular}{|lc|lcr|}
\multicolumn{2}{|c|}{ Todarodes pacificus $^{\mathrm{a}}$} & & \multicolumn{2}{c|}{ Dosidicus gigas } \\
Developmental category & Stage & & Developmental category & Stage \\
\cline { 1 - 1 } Fertilization-meiosis & $1-3$ & & Meiosis-blastodisc & $1-3$ \\
Cleavage & $4-10$ & & Cleavage & $4-10$ \\
Germ layers-blastoderm & $11-15$ & & Germ layers-blastoderm & $11-15$ \\
Organogenesis & $16-26$ & & Organogenesis & $16-19$ \\
& & & Pigmentation & $20-26$ \\
aWatanabe et al. (1996) & & & \\
\hline
\end{tabular}

\section{Temperature control}

Temperature control was accomplished with a combination of incubators, ambient room temperatures, and a temperature-control apparatus using Peltier devices that could maintain 4 individual dishes at different temperatures.

Temperatures were recorded every 1 to $2 \mathrm{~h}$ at the beginning of experiments, and if they were stable, once per day thereafter. Temperatures were taken to be the mean of measured temperatures throughout the experiment. Standard deviations calculated for the duration of the experiment were generally $<1^{\circ} \mathrm{C}$, although one $5^{\circ} \mathrm{C}$ treatment had a standard deviation of $1.18^{\circ} \mathrm{C}$. Ambient room temperature treatments displayed greater variability, with standard deviations of 1 to $3^{\circ} \mathrm{C}$ (means from 18.5 to $19.5^{\circ} \mathrm{C}$ ). One $29^{\circ} \mathrm{C}$ treatment had a standard deviation of $3.01{ }^{\circ} \mathrm{C}$ due to technical problems with the Peltier-based temperature-control apparatus (see 'Results').

\section{Analysis of temperature at the pycnocline}

Hydrographic data (depth, temperature, salinity) from the World Ocean Database for 2000 to 2009 were binned into $1 \mathrm{~m}$ depth-bins using original scripts written in Matlab. Depth at the thermocline and pycnocline were calculated for each profile as the depth at which the vertical derivative of temperature or density, respectively, was maximal. These values were imported into Ocean Data View for plotting. Depth of the pycnocline is typically equivalent to thermocline depth in oceanic waters (Pond \& Pickard 1983). Therefore, depth of the thermocline was used in the final analysis as a proxy for depth at the pycnocline because the amount of available temperature data far exceeded that of salinity data.

\section{RESULTS}

\section{Embryonic staging}

Following Yatsu et al. (1999), results are presented according to Watanabe's (1996) 34 developmental stages for Todarodes pacificus. However, 2 observations led to slight modifications of the original organization of these stages into 4 developmental categories.

First, control experiments carried out without the addition of sperm (SC08 and HMB09) revealed that unfertilized eggs underwent perivitelline expansion after addition of powdered oviducal gland and reliably developed to the formation of a blastodisc (Fig. 2). Because fertilization was not required for these events, Watanabe's Stages 1-3 'Fertilization and Meiosis' can be renamed 'Meiosis-Blastodisc' (Table 3).

Second, Watanabe's Stages 16 to 26 'Organogenesis' are divided into 2 categories: Stages 16 to 19 'Organogenesis' and Stages 20 to 26 'Pigmentation.' Development of pigment is defined by the appearance of eyes, chromatophores, and ink sac. This developmental milestone is easily identified and defines a clear developmental category.

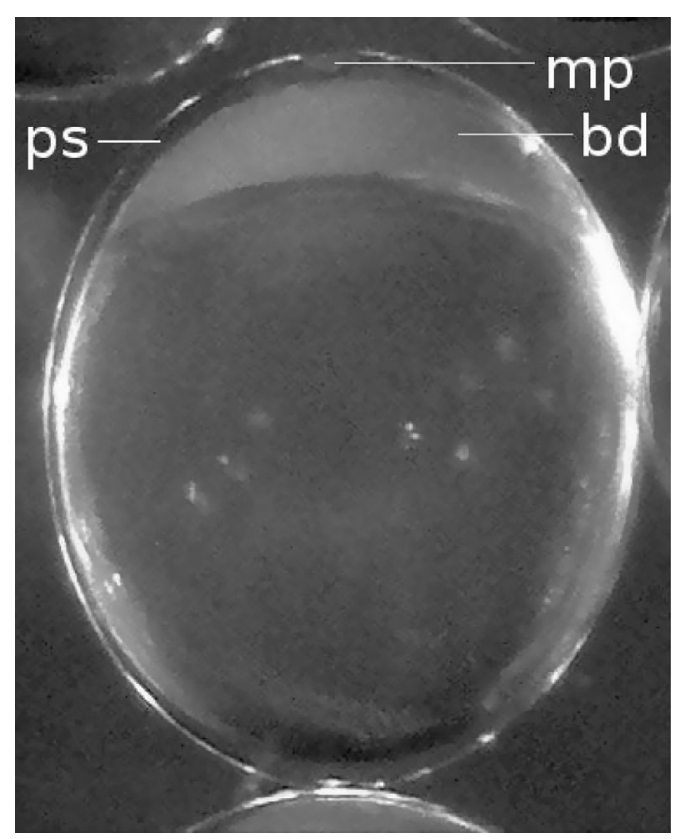

Fig. 2. Dosidicus gigas. Partial parthenogenesis in an unfertilized egg showing features previously associated with fertilization. mp: micropyle; bd: blastodisc; ps: expanded perivitelline space 


\section{Temperature effects}

Embryos maintained at cold temperatures consistently developed more slowly than did warm embryos. This trend can be seen for all 5 developmental categories in SD10 (Fig. 3). Development through the pigmentation stages was not evident below $10^{\circ} \mathrm{C}$, and hatching was not observed below $15^{\circ} \mathrm{C}$ (Fig. 3). In general, development through all categories was most successful in the range of 15 to $20^{\circ} \mathrm{C}$ (Fig. 4). Development did not proceed beyond cleavage at high temperature $\left(30^{\circ} \mathrm{C}\right)$ or beyond organogenesis at low $\left(5^{\circ} \mathrm{C}\right)$ temperature extremes. Even at the most favorable temperatures, fewer than half of the fertilized eggs exhibited cleavage, and less than a third reached blastoderm formation. Only about 10\% entered organogenesis, and half or fewer of these developed pigmentation and hatched successfully.

Hatching was observed only over the temperature range of 15 to $25^{\circ} \mathrm{C}$ (Fig. 5). In one experiment (SC08), embryos at $10^{\circ} \mathrm{C}$ reached Stage 22, a stage at which embryos at other temperatures hatched successfully (Fig. 4). Development at $10^{\circ} \mathrm{C}$ stopped at this point for unknown reasons, and no hatching occurred.
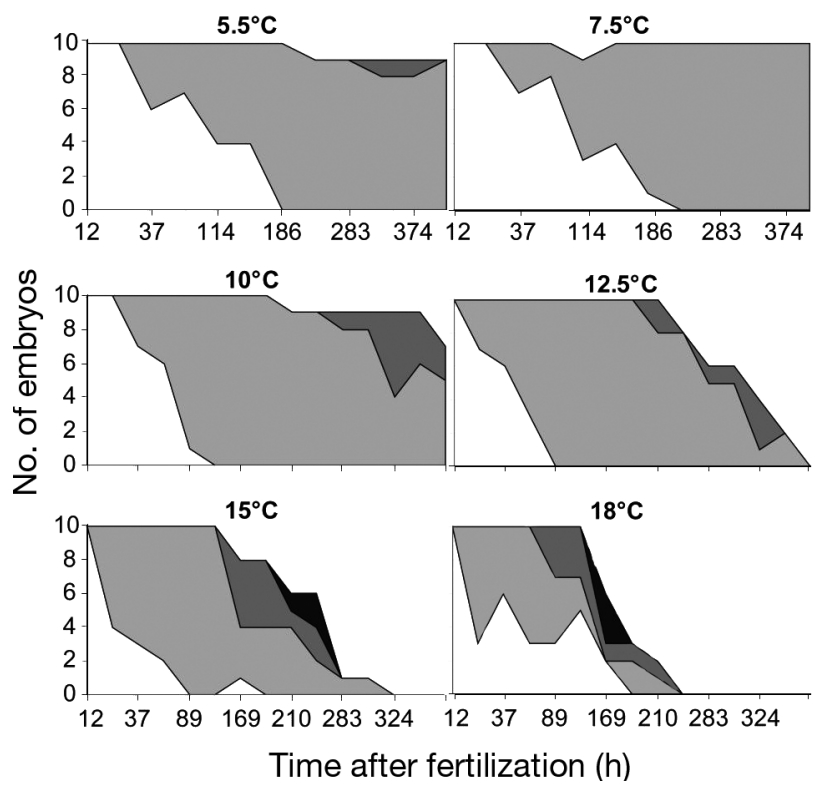

Fig. 3. Dosidicus gigas. Effect of temperature on developmental rate by category. The category of each of 10 cleaving embryos (data from San Diego 2010 station, SD10) is plotted against time after fertilization, beginning $12 \mathrm{~h}$ after fertilization. Observation times for 5.5 and $7.5^{\circ} \mathrm{C}$ were slightly different than those for the remaining 4 temperature treatments. White indicates blastoderm formation, light gray is organogenesis, dark gray is pigmentation, and black is hatching

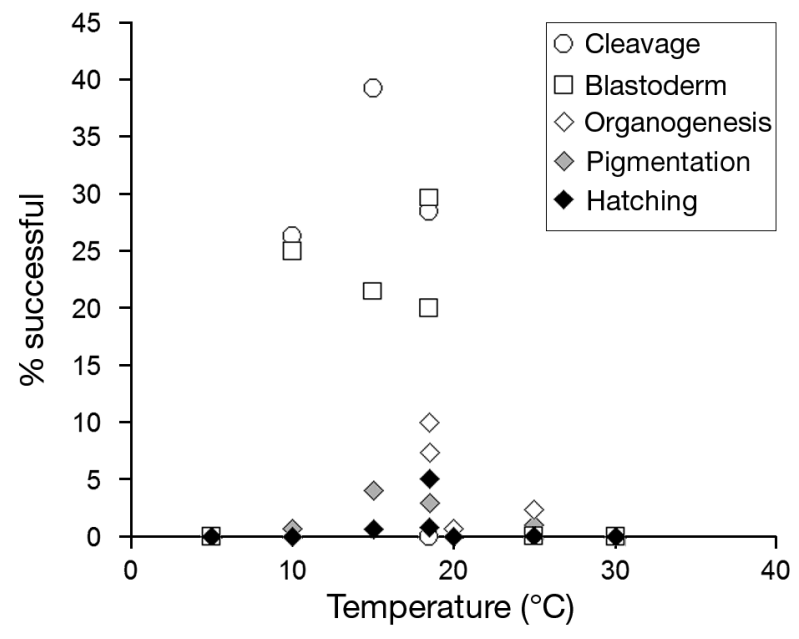

Fig. 4. Dosidicus gigas. Effect of temperature on developmental success. Percent successful development of gametes (data from Soquel Canyon 2008, SC08) was recorded for each category: cleavage, blastoderm formation, organogenesis, pigmentation, and hatching. Each point represents a single dish of eggs. The number of embryos observed in each category was divided by the total number of eggs in the dish

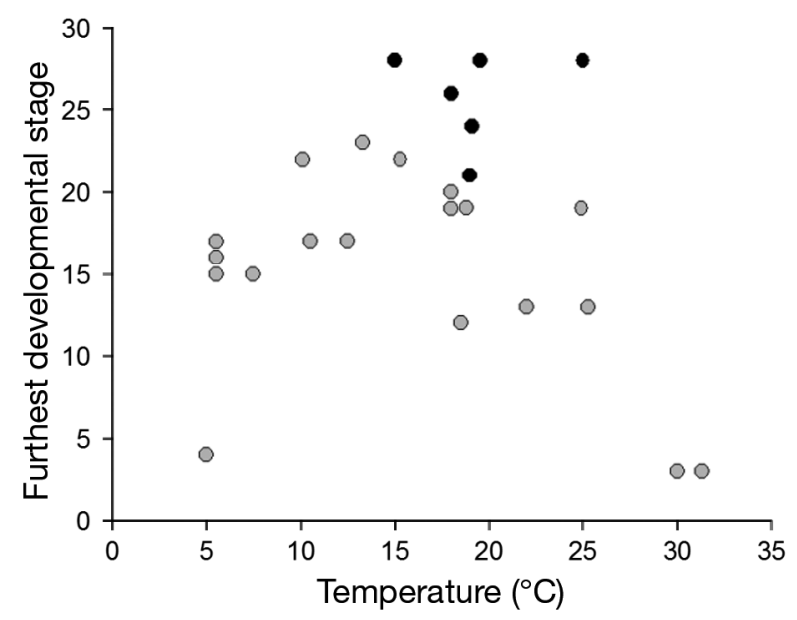

Fig. 5. Dosidicus gigas. Effect of temperature on developmental success. Furthest stage reached was plotted against temperature for gametes from the Farallon Basin (FB08), Soquel Canyon (SC08), and San Diego (SD10). Each point represents the most advanced embryo observed in a single dish

of eggs: (๑) hatching occurred; $(\bigcirc)$ no hatching observed

Identification of the 'natural' stage for hatching in ommastrephids is difficult. In the literature, ommastrephid hatching has generally been reported no earlier than Stage 26, although artificially fertilized eggs always seem to hatch before naturally deposited ones (Todarodes pacificus, Watanabe et al. 1996; Dosidicus gigas, Staaf et al. 2008). Classifying Stage 20 hatchlings (Fig. 5) as premature is therefore tempting, but too little is known about this group of squid to allow such a definition. 


\section{DISCUSSION}

\section{Artificial fertilization technique}

Several observations are of practical utility to future artificial fertilization work with Dosidicus gigas. Eggs can be kept at approximately 5 to $10^{\circ} \mathrm{C}$ for up to $2 \mathrm{~d}$ and remain viable, and sperm can be stored even longer (Huffard et al. 2007). These relatively long storage times allow gametes to be collected at sea and then transported over a considerable distance before fertilization is carried out, thereby permitting relevant studies to be done at a shore-based laboratory rather than on a research vessel.

Results of the present study support those of Ikeda et al. (1993) and show that sperm taken directly from mature males or from sperm storage-sites in females can be used to fertilize eggs. Thus, at a minimum, only one mature, mated female is necessary to perform artificial fertilization. Eggs from Stage V females (rather than IV) are recommended, but considerable variability between individual females may also exist, even between those at the same maturity state. These observations are in congruence with classical studies of early development (Kagan 1935).

Successful development of squid embryos requires chorion expansion, which in turn requires a suitable, presumably chemical, stimulus that is a component of the natural, gelatinous material produced by a female during egg laying. Artificial fertilization has successfully employed additions of agarose (Klein \& Jaffe 1984), bovine serum albumin (BSA) (Crawford 2002), and lyophilized oviducal gland (Arnold \& O'Dor 1990, Sakurai et al. 1995, Yatsu et al. 1999). In the present study, chorion expansion did not occur with agarose or BSA and only did so with lyophilized oviducal gland (Staaf 2010). These results may be broadly indicative of ommastrephids, and perhaps other oegopsid squids, as successes with agarose and BSA were found only in loliginids. As previously reported (Staaf et al. 2008), oviducal gland powder from Dosidicus gigas works as well as, but not better than, that from Ommastrephes bartramii (Yatsu et al. 1999) for fertilizing $D$. gigas eggs, which suggests that there is no species-specific component of the jelly in regard to fertilization.

Despite the use of sterile plastic-ware and antibiotics, microbial contamination remained a prominent concern. Given the apparent beneficial effects of antibiotics on early development (Table 2), systematic testing of specific antibiotics, concentrations and application times would be extremely valuable. Inter- estingly, the intact gelatinous matrix of a natural ommastrephid egg mass, generated by oviducal and nidamental glands, appears to protect the eggs within from microbial infection (Durward et al. 1980, Bower \& Sakurai 1996, Staaf et al. 2008). Understanding this natural protective mechanism would greatly expedite artificial fertilization studies.

\section{Partial parthenogenesis}

Watanabe et al. (1996) indicated that fertilization is followed by the appearance of the micropyle, and post-fertilization development was associated with expansion of the perivitelline space (Ikeda et al. 1993, Watanabe et al. 1996). In the present study, micropyles were also observed in unfertilized eggs of Dosidicus gigas (Fig. 2). This observation has also been noted for unfertilized loliginid eggs (Arnold \& Williams-Arnold 1976). The present study shows that expansion of the perivitelline space of unfertilized eggs can be stimulated simply by addition of oviducal gland powder.

Blastodisc formation was routinely observed in unfertilized eggs exposed to seawater and oviducal gland powder. Similar development of unfertilized eggs to the blastodisc stage, but not into cleavage, has been shown in teleost fishes (Kagan 1935, Okada 1961). In the case of Fundulus heteroclitus (Kagan 1935), once unfertilized eggs have developed blastodiscs, they cannot be fertilized, and the 'fertilizable life' of a F. heteroclitus egg is therefore only 15 to 20 min. Determining whether early parthenogenesis has also been inhibiting artificial fertilization for Dosidicus gigas would be important.

\section{Temperature and development}

This study represents the most thorough study to date of temperature effects on the embryonic development of Dosidicus gigas. Results indicate that temperatures below $15^{\circ} \mathrm{C}$ and above $25^{\circ} \mathrm{C}$ are not permissive of complete in vitro development and hatching, and at $15^{\circ} \mathrm{C}$, development is slower and less successful than at higher temperatures (Figs. 4 \& 5). These findings agree with results from the ommastrephid Illex coindetii that showed no hatching at $10^{\circ} \mathrm{C}$ and slow but successful development at $15^{\circ} \mathrm{C}$ (Boletzky et al. 1973). The upper thermal limit of about $25^{\circ} \mathrm{C}$ for successful late-stage development and hatching is close to the $26^{\circ} \mathrm{C}$ limit reported by Arnold \& O'Dor (1990) for the ommastrephid squid Sthenoteuthis 
oualaniensis, a close relative of D. gigas that shares its range in the Eastern Tropical Pacific.

This upper limit derived from in vitro studies is consistent with what is known about natural development. The only egg mass found in the wild to be positively associated with Dosidicus gigas occurred near the middle of the Guaymas Basin of the Gulf of California, just below the mixed surface layer at a pycnocline of $17 \mathrm{~m}$ depth and a temperature of 25 to $27^{\circ} \mathrm{C}$ (Staaf et al. 2008). Genetically identified embryos in this egg mass were all Stage 25, and hatching was imminent. A pelagic egg mass of similar size, shape and consistency was also reported by recreational divers in September 2009 off the Pacific Coast of Baja California Sur at a depth of $\sim 15 \mathrm{~m}$ and a temperature of 24 to $27^{\circ} \mathrm{C}$ (B. Caporale pers. comm.), but positive identification of species was not made. Whether these egg masses were spawned at the same depth and temperature as where they were discovered is not known.

\section{Spawning habitat, migrations and range extensions}

Adults of Dosidicus gigas in the Gulf of California undergo regular vertical migrations that can span a temperature range from at least 7 to $30^{\circ} \mathrm{C}$ (Gilly et al. 2006b, W. F. Gilly unpubl.). However, temperatures $>23^{\circ} \mathrm{C}$ tend to be avoided (Davis et al. 2007), and this value is comparable to the upper limit for successful embryonic development and hatching. Although limitation due to low temperature is not obvious in the case of adult squid (see also Zeidberg \& Robison 2007), temperatures $<15^{\circ} \mathrm{C}$ appear to prohibit complete embryonic development and hatching (as shown by this study) and survival of hatchlings (Staaf et al. 2008). This differential temperature limitation at different points in the life cycle may restrict the range over which $D$. gigas can reproduce.

Spawning in the laboratory by another ommastrephid species, Illex illecebrosus, led O'Dor \& Balch (1985) to hypothesize that females deposit negatively buoyant egg masses near the surface, where the gelatinous matrix quickly absorbs seawater. This absorption increases the spacing between embryos for proper ventilation and serves to counteract the specific gravity of the embryos (Lee \& Strathmann 1998). The egg mass, originally denser than seawater, sinks but becomes neutrally buoyant as it swells and eventually settles near the pycnocline. This subsurface position may protect the egg masses of ommastrephids, which are more fragile than the floating egg masses of some other oceanic squids (Guerra et al. 2002, Staaf et al. 2008), from potential damage by greater shear forces and UV irradiation at the sea surface. If the sharp density gradient at the pycnocline sets the vertical position of a Dosidicus gigas egg mass in the water column, then these data suggest that successful embryonic development can occur only in those areas of the eastern Pacific where temperature at the pycnocline is between 15 and $25^{\circ} \mathrm{C}$.

Fig. 6A maps the average temperature at the thermocline (a proxy for the pycnocline, see 'Materials and methods') during most of the year (November to June). Although areas where temperature at the thermocline regularly reaches $25^{\circ} \mathrm{C}$ are not apparent, the lower thermal limit for development (thermocline at $15^{\circ} \mathrm{C}$ ) is a prominent feature in the latitude range of 30 to $37^{\circ} \mathrm{N}$ during this time of year. During the remainder of the year (July to October, Fig. 6B) the boundary of this lower limit moves substantially northward, up to $43^{\circ} \mathrm{N}$. For these summer months, the $15^{\circ} \mathrm{C}$ thermocline lies ca. $500 \mathrm{~km}$ off most of the California coast. Seasonal oscillation in latitude of this feature appears to be greatest at a longitude of $\sim 130^{\circ} \mathrm{W}$ (Fig. 6C).

These data indicate that a vast area that may be suitable for development of Dosidicus gigas embryos exists seasonally relatively close to the California coast. Although paralarvae of this species have not been identified in US waters (Watson \& Manion 2011), sampling in this putative seasonal spawning area has not been reported. In situ sampling between July and October in the area bounded by the $15^{\circ} \mathrm{C}$ thermocline in Fig. 6B will be essential to a scientific understanding of this invasive predator's life cycle.

Dosidicus gigas has expanded its range to latitudes above $40^{\circ} \mathrm{N}$ in coastal waters over the last decade (Cosgrove 2005, Wing 2006, Zeidberg \& Robison 2007). In light of the lower thermal limit for embryonic development, adult squid occupying this coastal region must migrate either south or west to spawn in suitable habitat, migrations that would cover considerable distances. Based on tagging studies, adult D. gigas clearly can undergo long-distance horizontal migrations at sustained speeds of at least $30 \mathrm{~km}$ $\mathrm{d}^{-1}$ (Markaida et al. 2005, Gilly et al. 2006b), with the longest migration recorded being from Monterey, California, USA, to Ensenada, Mexico, a minimum distance of $600 \mathrm{~km}$ in $17 \mathrm{~d}$ (J. Stewart pers. comm.).

Such performance would allow migration between the current northern limit for adult Dosidicus gigas $\left(\sim 50^{\circ} \mathrm{N}\right.$, Vancouver Island) and established spawning habit in coastal waters off Baja California, a distance of some $2400 \mathrm{~km}$, in about $70 \mathrm{~d}$. Migration to the closest border of the proposed northern offshore 
A

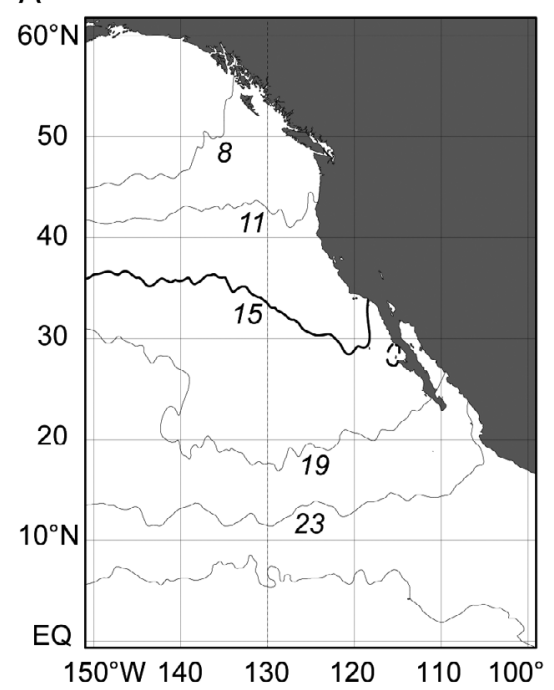

B

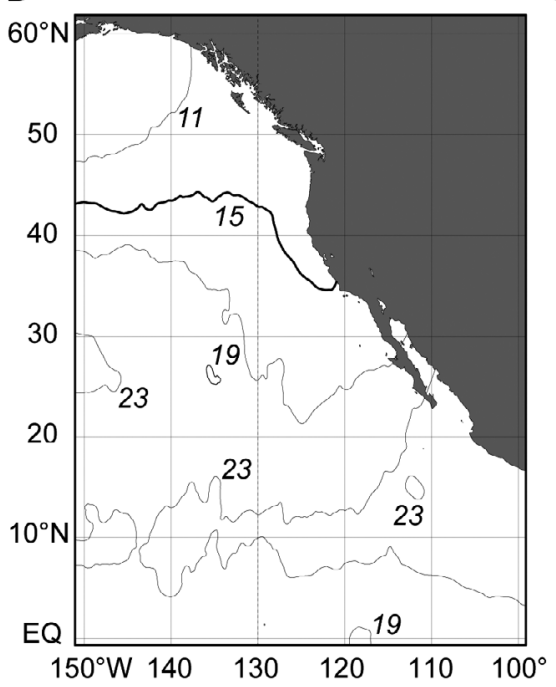

C

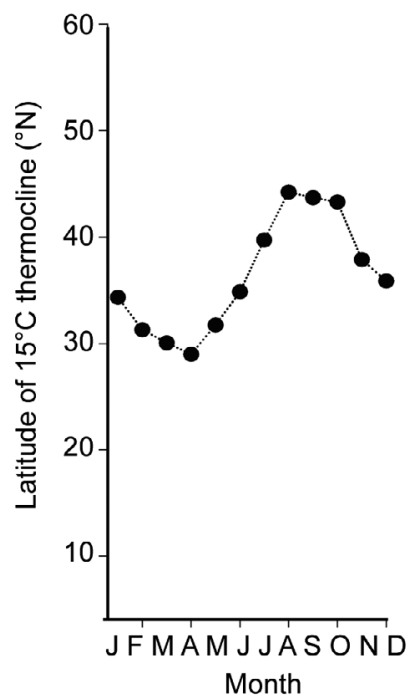

Fig. 6. Temperature at the depth of the thermocline, which was used as a proxy for the pycnocline (see 'Materials and methods: Analysis of temperature at the pycnocline') during (A) November to June and (B) July to October. The $15^{\circ} \mathrm{C}$ isotherm is emphasized. (C) Monthly position (latitude) of the $15^{\circ} \mathrm{C}$ thermocline measured at $130^{\circ} \mathrm{W}$

spawning area $\left(43^{\circ} \mathrm{N}, 130^{\circ} \mathrm{W}\right)$ would cover only half this distance. Thus, a squid born in either spawning area could easily make a feeding migration to the Pacific Northwest and return to a suitable spawning habitat in order to reproduce during a lifespan of 1 to 2 yr (Markaida et al. 2004).

Putative northern spawning grounds lie $500 \mathrm{~km}$ offshore within the oceanic portion of the California Current, which extends from the surface to $300 \mathrm{~m}$ depth and flows south throughout the year (Lynn \& Simpson 1987). Dosidicus gigas egg masses would be found at the pycnocline and paralarvae would likely occupy the upper $100 \mathrm{~m}$ of this region (Nesis 1970). In general, the peak speed of the California Current is $\sim 10 \mathrm{~cm} \mathrm{~s}^{-1}$ (Marchesiello et al. 2003), and at a distance of $150 \mathrm{~km}$ offshore of central California, the equatorward speed at pycnocline depth is 5 to $7 \mathrm{~cm}$ $\mathrm{s}^{-1}$ (Carr et al. 2008). In southern California, current speeds measured $250 \mathrm{~km}$ offshore exhibit seasonal variation, from $2-4 \mathrm{~cm} \mathrm{~s}^{-1}$ in the fall to $7-11 \mathrm{~cm} \mathrm{~s}^{-1}$ in the summer (Bray et al. 1999).

Considering the most rapid current possible and a conservative estimate of $10 \mathrm{~d}$ from spawning to hatching (at a temperature of $15^{\circ} \mathrm{C}$, see Fig. 3), an egg mass of Dosidicus gigas could be advected about $80 \mathrm{~km}$ to the south. Hatchlings are not strong swimmers (Staaf 2010) and would likely be carried this distance before developing the ability to counteract this current by swimming either directly against the flow or vertically into a different region, such as the poleward coastal California Undercurrent. The age at which $D$. gigas paralarvae develop the capacity to swim against a current is not known, but it could be at around $2 \mathrm{mo}$, the age at which the ommastrephid Illex argentinus develops large fins and transitions from a bell-shaped to a spindle-shaped mantle, suggesting a lifestyle change from planktonic to nektonic (Vidal 1994). Hatchlings of D. gigas born offshore of northern California might thus be swept up to $500 \mathrm{~km}$ south in the early part of their lives; however, they would still find themselves much farther north than paralarvae spawned off Baja California, the nearest area with permissive conditions for embryonic development on a year-round basis.

A potential for seasonal spawning in the area offshore of the California coast may thus be an important factor in supporting Dosidicus gigas populations that have invaded coastal waters of the Pacific Northwest since 2005 (Zeidberg \& Robison 2007). Suitable spawning habitat in the southern hemisphere in relation to putative range expansion is an important question that merits consideration, but a current shortage of hydrographic data in the southern hemisphere precluded examination of this issue. Oceanographic processes that determine temperature at the pycnocline and thereby define spawning habitat are not static, and the stability of this habitat will depend on a number of variable drivers, including temperature, currents and winds. Long-term fluctuations in any of these physical processes may play a causal role in episodic range extensions through expansion or contraction of spawning habitat that lies within a feasible migratory distance from productive coastal foraging areas. 
Acknowledgements. C. Widmer kindly shared his husbandry experience and incubators. C. Salinas, R. RamirezRojo, S. Camarillo-Coop, and A. Nyack assisted with conducting artificial fertilization experiments in the Gulf of California. J. Lee built the Peltier-based temperature control device. The authors thank B. Mate, Oregon State University, for the invitation to work on the 'Pacific Storm' and L. Ballance, Southwest Fisheries Science Center, for the opportunity to work on the 'MacArthur II'. They also thank the crews of all vessels involved in this study for their generosity and assistance; this work could never have been done without them. The authors acknowledge J. Field and J. Stewart for collection of gametes, J. Phillips and R. Brodeur for adult samples, and S. Arkhipkin for critical comments. A. Booth and P. Daniel provided invaluable assistance by writing Matlab scripts and creating figures. This work was supported by funding from Stanford University Dean of Humanities and Sciences, National Science Foundation (OCE 0526640), California Sea Grant and Ocean Protection Council, and David and Lucille Packard Foundation (no. 2005-28000).

\section{LITERATURE CITED}

Anderson CIH, Rodhouse PG (2001) Life cycles, oceanography and variability: ommastrephid squid in variable oceanographic environments. Fish Res 54:133-143

Arnold JM (1965) Normal embryonic stages of the squid, Loligo pealeii (Lesueur). Biol Bull 128:24-32

Arnold JM (1974) Embryonic development of the squid. In: Arnold JM, Summers WC, Gilbert DL, Manalis RS, Daw NW, Lasek RJ (eds) A guide to laboratory use of the squid Loligo pealeii. Marine Biological Laboratory, Woods Hole, MA, p 24-44

Arnold JM, O'Dor RK (1990) In vitro fertilization and embryonic development of oceanic squid. J Cephalopod Biol 1: 21-36

Arnold JM, Williams-Arnold LD (1976) The egg cortex problem as seen through the squid eye. Am Zool 16:421-446

Bazzino G, Salinas-Zavala C, Markaida U (2007) Variability in the population structure of jumbo squid (Dosidicus gigas) in Santa Rosalía, central Gulf of California. Cienc Mar 33:173-186

Bower JR, Sakurai Y (1996) Laboratory observations on Todarodes pacificus (Cephalopoda: Ommastrephidae) egg masses. Am Malacol Bull 13:65-71

$>$ Bray NA, Keyes A, Morawitz WML (1999) The California Current system in the Southern California Bight and the Santa Barbara Channel. J Geophys Res 104:7695-7714

Caddy JF, Rodhouse PG (1998) Cephalopod and groundfish landings: evidence for ecological change in global fisheries? Rev Fish Biol Fish 8:431-444

Camarillo-Coop S, De Silva-Dávila R, Hernández-Rivas ME, Durazo-Arvizu R (2006) Distribution of Dosidicus gigas paralarvae off the west coast of the Baja California peninsula, Mexico. In: Olson RJ, Young JW (eds) The role of squid in open ocean ecosystems. GLOBEC Report 24:7-8

> Camarillo-Coop S, Salinas-Zavala CA, Manzano-Sarabia M, Aragón-Noriega A (2011) Presence of Dosidicus gigas paralarvae (Cephalopoda: Ommastrephidea) in the central Gulf of California, Mexico related to oceanographic conditions. J Mar Biol Assoc UK 91:807-814

Carr SD, Capet XJ, McWilliams JC, Pennington JT, Chavez
FP (2008) The influence of diel vertical migration on zooplankton transport and recruitment in an upwelling region: estimates from a coupled behavioral-physical model. Fish Oceanogr 17:1-15

Clarke MR (1966) A review of the systematic and ecology of oceanic squids. Adv Mar Biol 4:147-187

Cosgrove JA (2005) The first specimens of Humboldt squid in British Columbia. PICES Press 13:30-31

> Crawford K (2002) Culture method for in vitro fertilization to hatching of the squid, Loligo pealeii. Biol Bull 203: 216-217

> Davis RW, Jaquet N, Gendron D, Markaida U, Bazzino G, Gilly W (2007) Diving behavior of sperm whales in relation to behavior of a major prey species, the jumbo squid, in the Gulf of California, Mexico. Mar Ecol Prog Ser 333: 291-302

Durward RD, Vessey E, O'Dor RK, Amaratunga T (1980) Reproduction in the squid, Illex illecebrosus: first observations in captivity and implications for the life cycle. ICNAF Sel Pap 6:7-13

Field JC, Baltz K, Phillips AJ, Walker WA (2007) Range expansion and trophic interactions of the jumbo squid, Dosidicus gigas, in the California Current. CalCOFI Rep 48:131-144

Field JC, Baltz KA, Matsubu W, Gillespie GE, Stewart JS, Gilly WF, Walker WA (2010) Foraging ecology of the Humboldt squid in the California Current. North Pacific ecosystems today, and challenges in understanding and forecasting change, PICES-2010 Annual Meeting. North Pacific Marine Science Organization, Sidney, p 66. Available at http://www.pices.int/publications/book_of abstracts/PICES-2010-Book-of-Abstracts.pdf

Gilly WF (2006) Spreading and stranding of jumbo squid. In: Ecosystems observations for the Monterey Bay National Marine Sanctuary 2005, p 25-26. Available online at http://montereybay.noaa.gov/reports/2005/eco/ harvestedsp.html

> Gilly WF, Elliger CA, Salinas CA, Camarillo-Coop S, Bazzino G, Beman M (2006a) Spawning by jumbo squid Dosidicus gigas in the San Pedro Mártir Basin, Gulf of California, Mexico. Mar Ecol Prog Ser 313:125-133

Gilly WF, Markaida U, Baxter CH, Block BA and others (2006b) Vertical and horizontal migrations by the jumbo squid Dosidicus gigas revealed by electronic tagging. Mar Ecol Prog Ser 324:1-17

Guerra A, González AF, Rocha FJ, Sagarminaga R, Cañadas A (2002) Planktonic egg masses of the diamond-shaped squid Thysanoteuthis rhombus in the eastern Atlantic and the Mediterranean Sea. J Plankton Res 24:333-338

Huffard CL, Buck K, Robison B (2007) Assessment of Dosidicus gigas sperm longevity using fluorescence microscopy. California Cooperative Oceanic Fisheries Investigations (CalCOFI), San Diego, CA

> Ikeda Y, Shimazaki K (1995) Does nidamental gland jelly induce the formation of perivitelline space at fertilization in the squid Todarodes pacificus? J Mar Biol Assoc UK 75:495-497

Ikeda Y, Sakurai Y, Shimazaki K (1993) Fertilizing capacity of squid (Todarodes pacificus) spermatozoa collected from various sperm storage sites, with special reference to the role of gelatinous substance from oviducal gland in fertilization and embryonic development. Invertebr Reprod Dev 23:39-44

Kagan BM (1935) The fertilizable period of the eggs of Fun- 
dulus heteroclitus and some associated phenomena. Biol Bull 69:185-201

Klein KC, Jaffe LA (1984) Development of in vitro fertilized eggs of the squid Loligo pealeii, and techniques for dechorionation and artifical activation. Biol Bull 167:518

Lee CE, Strathmann RR (1998) Scaling of gelatinous clutches: effects of siblings' competition for oxygen on clutch size and parental investment per offspring. Am Nat 151:293-310

Lipiński MR, Underhill LG (1995) Sexual maturation in squid: quantum or continuum? S Afr J Mar Sci 15:207-223

Lynn RJ, Simpson JJ (1987) The California Current System: the seasonal variability of its physical characteristics. J Geophys Res 92:12947-12966

> Marchesiello P, McWilliams JC, Shchepetkin S (2003) Equilibrium structure and dynamics of the California Current System. J Phys Oceanogr 33:753-783

Markaida U, Sosa-Nishizaki O (2001) Reproductive biology of jumbo squid Dosidicus gigas in the Gulf of California, 1995-1997. Fish Res 54:63-82

Markaida U, Quiñónez-Velázquez C, Sosa-Nishizaki O (2004) Age, growth and maturation of jumbo squid Dosidicus gigas (Cephalopoda: Ommastrephidae) from the Gulf of California, Mexico. Fish Res 66:31-47

Markaida U, Rosenthal JJC, Gilly WF (2005) Tagging studies on the jumbo squid (Dosidicus gigas) in the Gulf of California, Mexico. Fish Bull 103:219-226

Naef A (1928) Die Cephalopoden. Fauna Flora Golf Neapal 35. R. Friedländer \& Sohn, Berlin

Nesis KN (1970) The biology of the giant squid of Peru and Chile, Dosidicus gigas. Oceanology 10:140-152 (in Russian)

> Nigmatullin CM, Markaida U (2009) Oocyte development, fecundity and spawning strategy of large sized jumbo squid Dosidicus gigas (Oegopsida: Ommastrephinae). J Mar Biol Assoc UK 89:789-801

> Nigmatullin CM, Nesis KN, Arkhipkin AI (2001) A review of the biology of the jumbo squid Dosidicus gigas (Cephalopoda: Ommastrephidae). Fish Res 54:9-19

O'Dor RK, Balch N (1985) Properties of Illex illecebrosus egg masses potentially influencing larval oceanographic distribution. NAFO Sci Counc Stud 9:69-76

O'Dor RK, Balch N, Foy EA, Hirtle RWM, Johnston DA, Amaratunga $\mathrm{T}$ (1982) Embryonic development of the squid, Illex illecebrosus, and effect of temperature on developmental rates. J Northw Atl Fish Sci 3:41-45

Okada S (1961) On the uninseminated egg and the egg with dead embryo of dog-salmon, Oncorhynchus keta (Walbaum). J Fac Agric Hokkaido Univ 51:551-558

Pond S, Pickard GL (1983) Introductory dynamical oceanography, 2nd edn. Butterworth-Heinemann, Oxford

Rosa R, Seibel BA (2010) Metabolic physiology of the Humboldt squid, Dosidicus gigas: implications for vertical migration in a pronounced oxygen minimum zone. Prog Oceanogr 86:72-80

Sakurai Y, Ikeda Y (1994) Laboratory rearing methods of Todarodes pacificus for the ecological study of life cycle. In: Yatsu A (ed) Proc Squid Stock Ocean Conditions 1993. National Research Institute for Far Sea Fisheries, Shimizu, p 51-69 (in Japanese)

Sakurai Y, Young RE, Hirota J, Mangold K, Vecchione M, Clarke MR, Bower J (1995) Artificial fertilization and development through hatching in the oceanic squids
Ommastrephes bartramii and Sthenoteuthis oualaniensis (Cephalopod: Ommastrephidae). Veliger 38: 185-191

Sakurai Y, Bower JR, Nakamura Y, Yamamoto S, Watanabe K (1996) Effect of temperature on development and survival of Todarodes pacificus embryos and paralarvae. Am Malacol Bull 13:89-95

Sakurai Y, Kiyofuji H, Saitoh S, Goto T, Hiyama Y (2000) Changes in inferred spawning areas of Todarodes pacificus (Cephalopoda: Ommastrephidae) due to changing environmental conditions. ICES J Mar Sci 57:24-30

Segawa S, Yang WT, Marthy HJ, Hanlon RT (1988) Illustrated embryonic stages of the eastern Atlantic squid Loligo forbesi. Veliger 30:230-243

Smith RJ, Hobson KA, Koopman HN, Lavigne DM (1996) Distinguishing between populations of fresh- and saltwater harbour seals (Phoca vitulina) using stable-isotope ratios and fatty acid profiles. Can J Fish Aquat Sci 53: 272-279

Staaf DJ (2010) Reproduction and early life of the Humboldt squid. PhD thesis, Stanford University, CA

Staaf DJ, Camarillo-Coop S, Haddock SHD, Nyack AC and others (2008) Natural egg mass deposition by the Humboldt squid (Dosidicus gigas) in the Gulf of California and characteristics of hatchlings and paralarvae. J Mar Biol Assoc UK 88:759-770

Boletzky SV, Rowe VL, Aroles L (1973) Spawning and development of the eggs in the laboratory, of Illex coindetii. Veliger 15:257-258

Vecchione M (1999) Extraordinary abundance of squid paralarvae in the tropical eastern Pacific Ocean during El Niño of 1987. Fish Bull 97:1025-1030

- Vidal EAG (1994) Relative growth of paralarvae and juveniles of Illex argentinus (Castellanos, 1960) in southern Brazil. Antarct Sci 6:275-282

Watanabe K, Sakurai Y, Segawa S, Okutani T (1996) Development of the ommastrephid squid Todarodes pacificus, from fertilized egg to rhynchoteuthion paralarva. Am Malacol Bull 13:73-88

Watase S (1891) Studies on cephalopods. I. Cleavage of the ovum. J Morphol 4:247-302

Watson W, Manion S (2011) Ichthyoplankton, paralarval cephalopod, and station data for surface (Manta) and oblique (bongo) plankton tows for California Cooperative Oceanic Fisheries Investigations Survey and California Current Ecosystem Survey cruises in 2008. NOAA Tech Memo NMFS-SWFSC-481

Wing BL (2006) Unusual invertebrates and fish observed in the Gulf of Alaska, 2004-2005. PICES Press 14:26-28

Wormuth JH (1976) The biogeography and numerical taxonomy of the oegopsid squid family Ommastrephidae in the Pacific Ocean. Bull Scripps Inst Oceanogr 23. University of California Press, Berkeley, CA

Yatsu A, Tafur R, Maravi C (1999) Embryos and rhynchoteuthion paralarvae of the jumbo flying squid Dosidicus gigas (Cephalopoda) obtained through artificial fertilization from Peruvian waters. Fish Sci 65:904-908

Young RE, Vecchione M (2009) Dosidicus gigas (Orbigny 1835), jumbo squid. Available at: tolweb.org/Dosidicus_ gigas/19945/2009.12.29

Zeidberg LD, Robison BH (2007) Invasive range expansion by the Humboldt squid, Dosidicus gigas, in the eastern North Pacific. Proc Natl Acad Sci USA 104:12948-12950 